\title{
The obesity epidemic: Is bariatric surgery the antidote?
}

\author{
Shahzeer Karmali MD ${ }^{1}$, Eldon Shaffer MD FRCPC ${ }^{2}$
}

\section{EPIDEMIOLOGY AND IMPACT OF OBESITY}

We live in a supersized world, where big is small, huge is medium and enormous is large. A recent addition to this environment was the Hardee's "Monster thickburger" boasting a gargantuan 1420 calories and $107 \mathrm{~g}$ of fat. Not only has this product taken off, customers have been literally devouring it, leading to a $20 \%$ increase in sales at Hardee's stores since its 2003 debut (1). Therefore, it is not surprising that in the United States, at least 131 million adults are overweight or obese, and obesity is the second most common cause of death in the United States (2). In Canada, the situation is similar, with almost $31 \%$ of Canadian adults classified as obese (3); indeed, obesity has doubled over a 13-year period from 1985 to 1998 (4). The health consequences of obesity are devastating and expensive, accounting for $2.4 \%$ of the total Canadian health care expenditures for all diseases and a direct cost of $\$ 1.8$ billion in 1998 (4). Furthermore, obesity is associated with many comorbid illnesses such as hypertension, hypertriglyceridemia, hyperlipidemia, hyperinsulinemia, coronary artery disease, stroke, osteoarthritis, sleep apnea, gastroesophageal reflux disease, pancreatitis and steatohepatitis, as well as breast, endometrial, prostate and colon cancer. These alone account for an additional 2.5 million deaths per year worldwide (5). Thus, organizations such as the National Institutes of Health and the Surgeon General of the United States have acknowledged the importance of the problem and have urged the development of public health strategies to curb the epidemic (6).

\section{CONSERVATIVE APPROACHES TO MANAGE OBESITY}

Many conservative approaches have been undertaken to reduce weight and, thus, ameliorate the detrimental effects of an excessive amount of body fat. Medical treatments for obesity seek to either decrease energy intake or increase energy expenditure. Those that decrease energy intake have a greater potential for causing acute weight loss than those that attempt an increase in energy expenditure. There are three key modalities: dietary intervention, physical activity and behaviour modification. Dietary intervention represents the cornerstone of conservative weight loss therapy, where the ultimate goal is to achieve negative energy balance by decreasing food intake. The second modality is physical activity (three to seven sessions $30 \mathrm{~min}$ to $60 \mathrm{~min}$ each) and aims to increase net energy expenditure. Most regimens combine dietary interventions and exercise in some fashion. The third modality is behaviour modification and is based on the classical conditioning principle that behaviours are often prompted by an antecedent event, and the link between the antecedent event and the behaviour becomes stronger with repetition. Disconnecting the triggers within this chain helps to diminish the strength of each trigger over time. However, even when combined, these first-line medical strategies may only be effective in some patients. The fact is, weight loss is frequently unsustainable, with only $5 \%$ to $10 \%$ of patients maintaining the lost weight for more than a few years (7). Additionally, such conservative measures do not sustain the improvements in obesity-related comorbidities such as hypertension, dyslipidemia, hyperinsulinemia and the progression to diabetes (8).

In situations where lifestyle changes (ie, diet, exercise and/or behaviour modification) are ineffective in yielding sustained weight loss, physicians often resort to drug therapy as a second-line conservative approach for weight reduction. Currently, the United States Food and Drug Administration has approved drugs in two classes for weight control. The first is an anoretic agent (sibutramine [9]) which acts a serotonin and norepinephrine reuptake inhibitor. The second is a malabsorptive agent (orlistat [10]) which inhibits gastric and pancreatic lipase. Although most patients lost $1.8 \mathrm{~kg}$ to $4.5 \mathrm{~kg}$ over one year using these agents, weight regain was high once these drugs were discontinued (11). Moreover, the risk-to-benefit ratio of drug therapy is still not predictable because sufficient long-term studies (greater than one year) are not yet available (12).

The conservative options outlined remain disappointing, with most patients either losing an inadequate amount of weight or (for those able to lose a significant amount of weight) experiencing total weight regain within a few years, an outcome termed the 'yo-yo' phenomenon (13).

${ }^{1}$ Department of Surgery, Division of General Surgery; ${ }^{2}$ Department of Medicine, Division of Gastroenterology, University of Calgary, Calgary, Alberta

Correspondence: Dr Eldon Shaffer, University of Calgary, Division of Gastroenterology, Health Science Centre, 3330 Hospital Drive Northwest,

Calgary, Alberta T2N 4N1. Telephone 403-210-9363, fax 403-210-9358, e-mail shaffer@ucalgary.ca

Received for publication January 2, 2005. Accepted February 23, 2005 


\section{SURGICAL MANAGEMENT OF OBESITY}

As a result of the overall failure of conservative treatments, particularly for the severely obese, there has been a resurgence of surgical approaches to managing the obese patient. In the United States, the number of patients undergoing bariatric surgery has increased almost exponentially in the past four years; approximately 100,000 weight reduction surgeries were performed in the United States in 2004 (14). Current surgical techniques for severe obesity are best classified as those that primarily effect restriction of the stomach size and hence provide early satiety (restrictive operation)' and procedures that primarily cause maldigestion and malabsorption (malabsorptive operations).

Restrictive operations serve primarily to limit food intake and do not interfere with the normal digestive processes. These procedures act to reduce gastric volume and, thereby, create a mechanical barrier to the ingestion of food, producing early satiety. Vertical banded gastroplasty, adjustable gastric banding and gastric bypass are the three restrictive options. Gastric banding and vertical band gastroplasty are technically simpler and have fewer complications than bypass, but are less effective in achieving and sustaining significant weight loss (15-18).

Malabsorptive operations act predominantly by reducing the absorption of calories and nutrients, and to a lesser extent by restricting food intake. Biliopancreatic diversion is the primary operation in this category. Malabsorptive operations cause a greater degree of weight loss (approximately 75\% excess weight) than gastric restrictive procedures, but are associated with abnormalities of malnutrition and complications (ie, stoma ulcers; flatulence; and loose, foul-smelling stools). The addition of a duodenal switch decreases protein deficiency and gastrointestinal side effects.

In the past five years, the laparoscopic approach has become increasingly available, with surgeons gaining more

\section{REFERENCES}

1. Numbers. Time Magazine. <www.time.com/time/archive/preview/ 0,10987,1022600,00.html> (Version current at March 14, 2005).

2. Mokdad AH, Serdula MK, Dietz WH, Bowman BA, Marks JS, Koplan JP. The spread of the obesity epidemic in the United States, 1991-1998. JAMA 1999;282:1519-22.

3. Statistics Canada. National population health survey. Report No: 82-F0001XCB. Ottawa, Ontario: 1994.

4. Birmingham CL, Muller JL, Palepu A, Spinelli JJ, Anis AH. The cost of obesity in Canada. CMAJ 1999;160:483-8.

5. Obesity: Preventing and managing the global epidemic. World Health Organization, Geneva, 2000. (WHO technical report series, No 894).

6. National Institutes of Health. Clinical guidelines on the identification, evaluation and treatment of overweight and obesity in adults. Bethesda, Maryland: National Institutes of Health, 1998.

7. Patterson EJ, Urbach DR, Swanstrom LL. A comparison of diet and exercise therapy versus laparoscopic Roux-en-Y gastric bypass surgery for morbid obesity: A decision analysis model. J Am Coll Surg 2003;196:379-84

8. Mitka M. Surgery for obesity: Demand soars amid scientific, ethical questions. JAMA 2003;289:1761-3.

9. Food and Drug Administration. FDA approves sibutramine to treat obesity. <www.fda.gov/bbs/topics/ANSWERS/ANS00835.html> (Version current at March 14, 2005).

10. Food and Drug Administration. FDA approves orlistat to treat obesity. <www.fda.gov/bbs/topics/ANSWERS/ANS00951.html> (Version current at March 14, 2005).

11. Bray GA. Drug treatment of obesity. Rev Endocr Metab Disord 2001;2:403-18 experience using these techniques. The benefits of such an approach are a decreased wound complication rate, a shorter hospital stay, less postoperative discomfort, higher patient acceptance and similar weight loss results compared with the open technique $(19,20)$. There is a steep learning curve in performing these operations, necessitating advanced laparoscopic skills (21).

The current consensus is that surgery is the only proven method of long-term weight loss for the large majority of morbidly obese patients (body mass index greater than $40 \mathrm{~kg} / \mathrm{m}^{2}$ ). It has the advantage of being a long-term treatment for a chronic health problem. This contrasts with the short-term benefits offered by medical management or lifestyle alterations. Bariatric surgery is associated with more substantial weight loss than conventional medical management (22). The outcome categories of hyperlipidemia, hypercholesterolemia and hypertriglyceridemia are significantly improved across all surgical procedures, with approximately $70 \%$ of patients exhibiting improvement $(23,24)$.

\section{CONCLUSIONS}

With the boom of 'monster burgers' and the desire to 'supersize', obesity has reached epidemic proportions in the western world and is beginning to be evident in developing countries. Conservative medical and behavioural interventions to date have been largely ineffective in this growing problem. Bariatric surgery is steadily becoming the most effective intervention in severe obesity for both weight loss and treating the perilous comorbidities associated with a markedly elevated body mass index. Faced with a growing legion of patients with extreme obesity, bariatric surgery may soon be the only cure for the 'battle of the bulge' pandemic.

12. Fisher BL, Schauer P. Medical and surgical options in the treatment of severe obesity. Am J Surg 2002;184(Suppl 6B):9S-16S

13. Stocker DJ. Management of the bariatric surgery patient. Endocrinol Metab Clin North Am 2003;32:437-57.

14. Steinbrook R. Surgery for severe obesity. N Engl J Med 2004:350:1075-9.

15. MacLean LD, Rhode BM, Sampalis J, Forse RA. Results of the surgical treatment of obesity. Am J Surg 1993;165:155-60.

16. Sugarman JR, Grossman DC. Trauma among American Indians in an urban county. Public Health Rep 1996;111:321-7.

17. Hall JC, Watts JM, O'Brien PE, et al. Gastric surgery for morbid obesity. The Adelaide Study. Ann Surg 1990;211:419-27.

18. Howard L, Malone M, Michalek A, Carter J, Alger S, Van Woert J. Gastric bypass and vertical banded gastroplasty - a prospective randomized comparison and 5-year follow-up. Obes Surg 1995;5:55-60.

19. Nguyen NT, Goldman C, Rosenquist CJ, et al. Laparoscopic versus open gastric bypass: A randomized study of outcomes, quality of life, and costs. Ann Surg 2001;234:279-89.

20. Schauer PR, Ikramuddin S, Gourash W, Ramanathan R, Luketich J. Outcomes after laparoscopic Roux-en-Y gastric bypass for morbid obesity. Ann Surg 2000;232:515-29.

21. Schauer P, Ikramuddin S, Hamad G, Gourash W. The learning curve for laparoscopic Roux-en-Y gastric bypass is 100 cases. Surg Endosc 2003;17:212-5.

22. Colquitt J, Clegg A, Sidhu M, Royle P. Surgery for morbid obesity. Cochrane Database Syst Rev 2003;(2):CD003641.

23. Buchwald $\mathrm{H}$, Avidor $\mathrm{Y}$, Braunwald E, et al. Bariatric surgery: A systematic review and meta-analysis. JAMA 2004;292:1724-37.

24. Gleysteen JJ, Barboriak JJ. Improvement in heart disease risk factors after gastric bypass. Arch Surg 1983;118:681-4. 




The Scientific World Journal
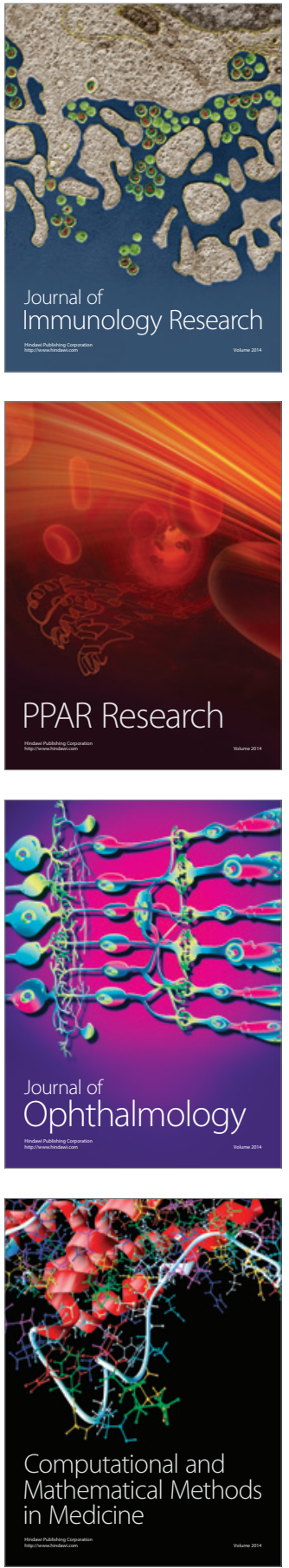

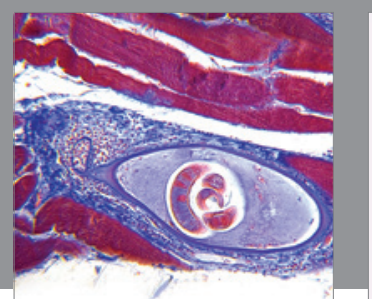

Gastroenterology Research and Practice

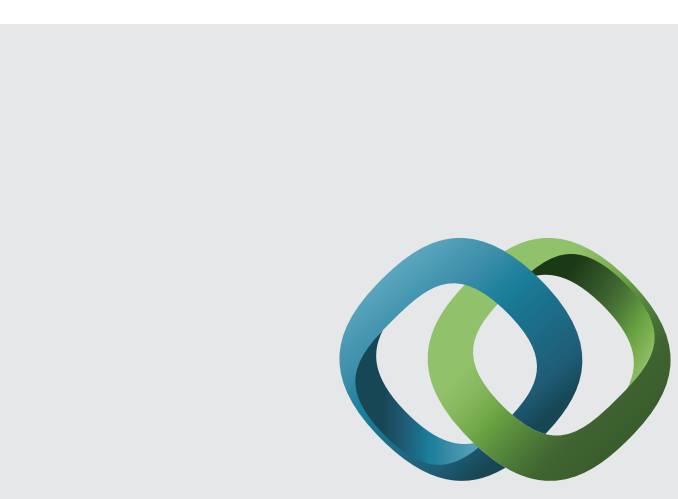

\section{Hindawi}

Submit your manuscripts at

http://www.hindawi.com
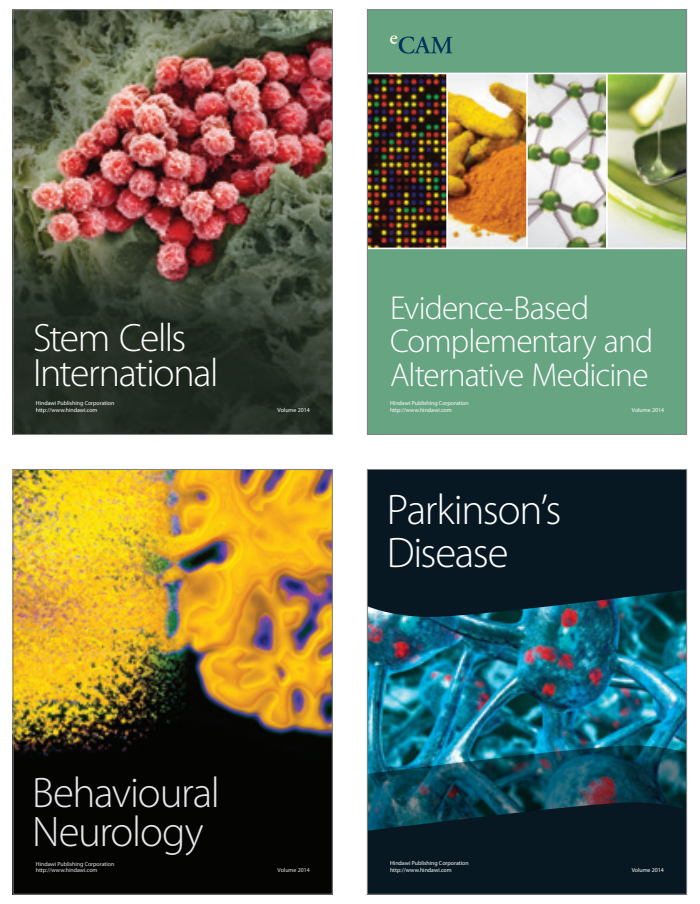
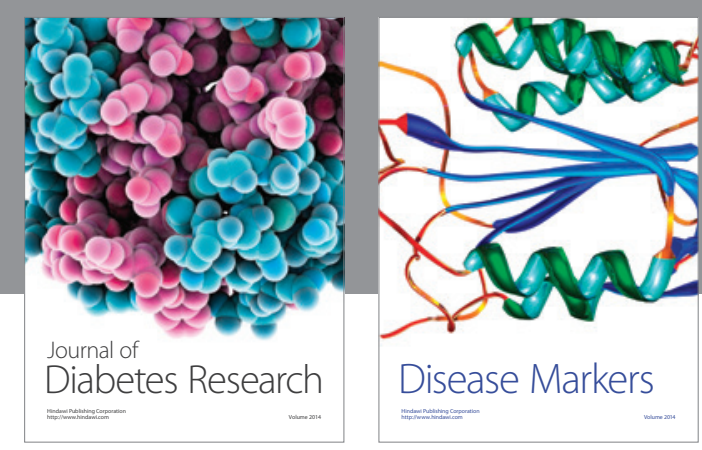

Disease Markers
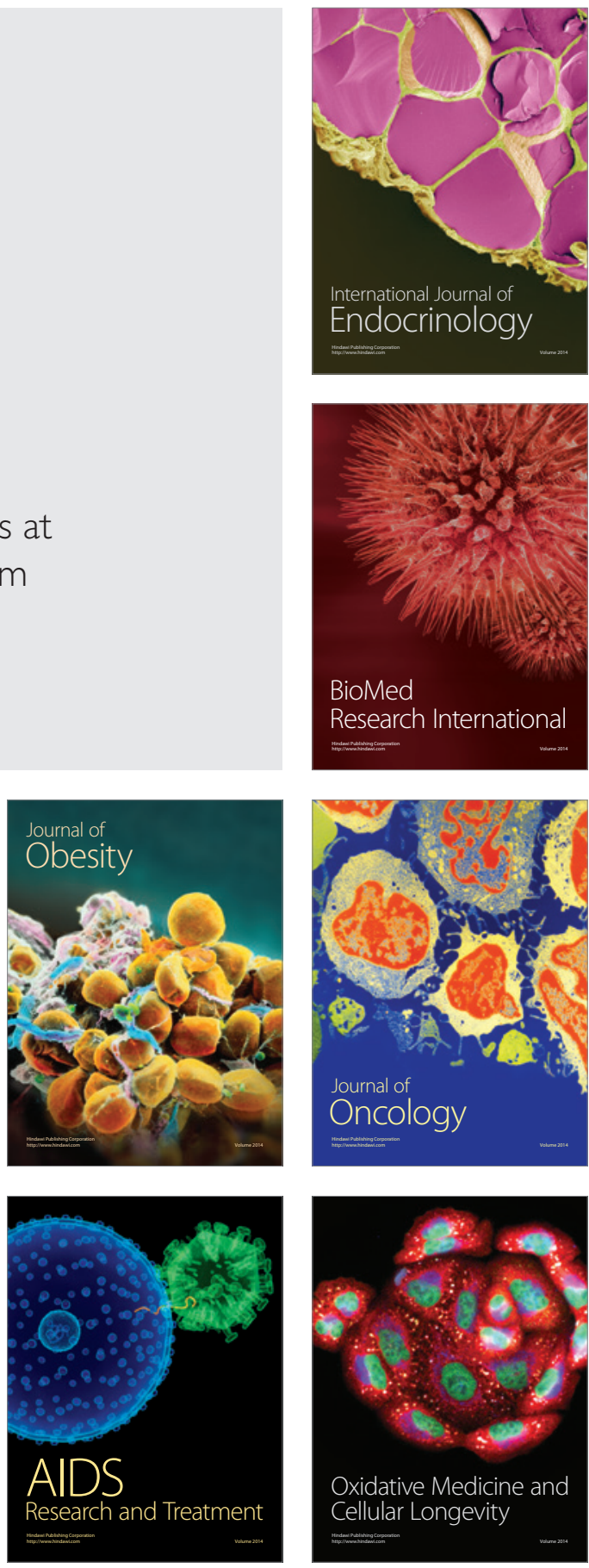